\title{
Aligning order picking methods, incentive systems, and regulatory focus to increase performance
}

\author{
Jelle de Vries*, René De Koster, Daan Stam
}

\begin{abstract}
A unique controlled field experiment investigates order picking performance (in terms of productivity and quality). We examined three manual picker-to-parts order picking methods (parallel, zone, and dynamic zone picking) under two different incentive systems (competitionbased versus cooperation-based) for pickers with different regulatory foci (prevention-focus versus promotion-focus). The study was carried out in a warehouse erected especially for the purposes of order picking research. Our results show that when using a parallel picking method a competitionbased incentive system increases productivity and quality compared to a cooperation-based incentive system, and that when using a zone picking method it is more productive to use a cooperationbased incentive system. This pattern of results was especially pronounced for pickers with a dominant promotion focus. Dominantly prevention focused pickers, however, were more productive with a cooperation-based incentive system, irrespective of the picking method. Additionally, a cooperation-based incentive system delivered a low quality performance in zone picking, but a high quality performance in dynamic zone picking. The analyses demonstrate that by aligning order picking methods, incentive systems and regulatory focus, warehouses can improve productivity and quality, and reduce wage costs by up to $20 \%$.
\end{abstract}

Keywords: behavioral operations, warehousing, order picking, incentives.

*Corresponding author: jvries@rsm.nl. 


\section{Introduction}

Against the backdrop of global economic challenge, warehouses are continuously investigating how operating costs can be reduced to remain competitive. At the same time, some warehouse operations face negative publicity concerning their human resource practices, while finding suitable employees is becoming more difficult. All of this is taking place while the market share of ecommerce is growing, which often implies that warehouses have to meet increasing customer demands by offering speedier delivery and tighter and more flexible delivery windows (Frazelle, 2002). This puts pressure on virtually all warehouse processes. One of these processes, order picking, the retrieval of a number of products from their storage locations in the warehouse to satisfy orders of specific customers, is an essential activity in the supply chain and accounts for up to $50 \%$ of the operating costs of a typical warehouse (Tompkins 2010). Due to this relatively large share of costs, order picking is an attractive area to take into consideration when searching for productivity improvements and potential cost-savings. Selecting an appropriate order picking method is instrumental in achieving this.

Most of the academic literature on order picking focuses on optimizing a specific aspect of a particular order picking method. Examples include routing (De Koster et al., 2007; Hwang et al., 2004; Petersen, 2004), storage assignment (Jarvis and McDowell, 1991), warehouse layout (Hsieh and Tsai, 2006), and zoning (Jane and Laih, 2005; Le-Duc and De Koster, 2005). This body of research is a major contribution to the field and has led to greater efficiency in those warehouses that have been able to successfully implement the findings in practice. However, surprisingly enough, one very important factor in order picking has been largely ignored: the people involved in order picking. De Koster et al. (2007) reported that less than 30 percent of the papers included in their literature review on warehouse order picking concerned picker-to-part order picking systems. This is probably because parts-to-picker systems are largely automated, which makes it easier and more attractive for researchers to accurately model the behavior of these systems. Still, most warehouses employ people for order picking (De Koster, 2007). Unfortunately even the literature that does focus on picker-to-part order picking systems primarily studies system design, planning, and control related issues, rather than how humans act within these systems. This shows that the importance of the human factor in order picking is not acknowledged.

In sharp contrast, based on a large number of studies we expect that human factors strongly affect performance in tasks such as order picking. Indeed, various behavioral factors have shown 
to influence performance. Examples are performance loss in group tasks (Erez and Somech, 1996) and the effect of goal setting in organizations (Locke, 1968). Compensation and incentive systems are among the most effective strategies to influence employee behavior, motivation, and performance (Guzzo et al., 1985). Examples of such systems are piece-rate pay systems (Lazear, 2000) in which individuals get (extra) pay-based on their individual performance and group compensation schemes in which the members of a team get (extra) pay-based on the performance of the team as a whole (DeMatteo et al., 1998). Interestingly, not all incentive systems lead to optimal performance under all conditions, and people respond differently to specific incentive systems (Wageman and Baker, 1997). Specifically, it appears that incentives oriented on the individual are especially effective under circumstances in which individuals work independently (Dobbins et al., 1991). In contrast, incentives directed at the group level are especially effective under circumstances that emphasize task interdependency (Wageman, 1995; Zingheim and Schuster, 2000). Individual characteristics also play a role. For instance, a major theory of individual differences, regulatory focus theory (Higgins, 1998), distinguishes between individuals that are oriented on achieving their personal ideals and ambitions using eager strategies (promotion focus) and individuals that are oriented on fulfilling their duties and obligations using vigilant strategies (prevention focus). Recent research shows that promotion-focused individuals are more motivated by individual incentive schemes, while prevention-focused individuals are more motivated by group incentive schemes (Beersma et al., 2013).

These research findings lead us to believe that incentive schemes may be an important facilitator of performance in order picking depending on the order picking method used and the characteristics of the individual picker. Three of the most common order picking methods are parallel picking, in which pickers work independently, zone picking, in which multiple pickers handle an order, and dynamic zone picking, which includes elements of both other picking methods. In terms of incentive schemes, individual incentive schemes should be especially motivating for promotion-focused individuals working in a parallel order picking system (since under this system pickers work highly independently) while group incentive schemes should be especially motivating for prevention-focused individuals working in a zone order picking system (since under this system pickers work highly interdependently). Moreover, for individuals working in a dynamic zone system both individual as well as group incentive schemes can be effective based on the individual characteristics of the picker; An individual incentive scheme is expected to be especially 
effective for promotion-focused pickers, while a group incentive scheme is expected to be especially effective for prevention-focused pickers. Thus, taking the incentive system and the regulatory focus of order pickers into consideration will enable us to assess more precisely which combinations of behavioral context and traditional order picking methods are especially fruitful.

Through an experimental approach that was inspired by the recently emerged field of behavioral operations, this study aims to bridge the gap between traditional models focusing on optimizing the order picking process and the order picking performance that can actually be observed in practice. By taking behavioral aspects (i.e. incentive schemes and picker characteristics) into consideration, we aim to obtain results that directly translate into practice. The experimental approach of this current study, featuring a specially erected full-size warehouse, is highly novel and should ensure that our findings are, to a large extent, directly generalizable to the practical setting of warehouses worldwide.

Our study makes both theoretical and practical contributions. Although theoretical research has established that an alignment between incentive systems, task, and person is important for optimal performance, the exact nature of this alignment is unclear. We offer a new model of the alignment of incentive systems and order picking tasks by focusing on cooperative and competitive incentive systems and their effectiveness under parallel, zone, and dynamic zone picking methods. This extends the more global models of incentives systems by adapting them to the domain of order picking. We also integrate individual differences in this equation. Specifically, we identify regulatory focus as a crucial individual difference and test its moderating effects on the influence of incentive systems. Together, this leads to a much-extended model of incentive systems that is specific to the domain of order picking.

Our contributions also extend theory. For instance, much of the research on incentive systems in Operations Management (OM) is theoretical in nature and our research extends this by detailing empirical evidence of the effects of incentive systems in actual order picking and how incentive systems depend on picking method and individual differences. From a managerial point of view, identifying under which circumstances different types of people reach their optimal performance levels could be particularly beneficial not only because companies could be aided in training and selecting the right employees for the job, or in determining which incentive system should be used in combination with which order picking method and type of employee, but also to explore the potential tradeoff between productivity and quality in the context of order picking. 
Quality has been scarcely researched in this context, and is therefore investigated from a more exploratory perspective. However, these aspects are also essential as companies have to operate with a simultaneous focus on profit, quality, and the wellbeing of their employees.

In the remainder of this paper, we first review the literature on order picking, incentive systems, and regulatory focus. Next, we introduce our hypotheses, describe our methodology and our performance measures. We then present our analyses and results. We conclude by discussing the practical impact of correctly aligning the picking method, the incentive system, and the regulatory focus of the individual pickers, and how our findings can be implemented in practice.

\section{Theory}

\subsection{Order picking}

As a pivotal step in a product's route to a customer, order picking can be regarded as a crucial warehouse operation. The full order picking process involves all steps from clustering and scheduling customer orders to disposing the picked articles. In many of these steps, a certain degree of automation is possible, but most warehouses employ humans as order pickers (De Koster, 2007). In this paper, we focus on the most common picking system, low-level picker-to-parts picking with multiple picks per route, in which the order picker has to walk along the aisles to fulfill the order by picking all specified items. This picking system contrasts with parts-to-picker systems that make use of automated storage and retrieval systems (AS/RS) or carousels (De Koster et al., 2007).

Various technological picking tools can be used in low-level picker-to-parts systems. For example, pickers can be aided by hand-held scanners, voice-terminals, or pick-to-light systems. Here, we only focus on the traditional order picking using a paper picking list. There are also various picking methods. In this study we include three of the most common methods: parallel picking, sequential zone (pick and pass) picking, and dynamic zone (bucket brigade) picking. In

parallel picking, pickers work on their own order from the beginning to the end. This means that the pickers work almost independently of each other. In sequential zone picking, the warehouse or aisle is divided into separate zones. Each picker is responsible for one zone, and an order is passed on to the picker in the next zone when the order is completed in the zone. If an order does not contain any lines to be picked in a particular zone, the order is passed on to the next zone immediately. If the picker in the next zone is still busy with a previous order, the current order can be 
placed in a buffer. In dynamic zone picking the volume determines the end of the zone, so there is no fixed zone limit. Rather than waiting at the zone limit until the upstream picker is finished with his/her zone, a picker will travel towards the upstream picker and the order will be transferred at the meeting point. Theoretically, this eliminates waiting time or large buffers between zones (Tompkins, 2010).

Research in order picking has helped practice in low-level picker-to-parts substantially in optimizing performance. Indeed, while most literature on order picking focuses on automated systems, much research is also available that is relevant for low-level picker-to-parts systems. These studies focus on various aspects of the order picking process to increase efficiency. Examples include the layout of the picking area (Caron et al., 2000), the product storage strategy (Jarvis and McDowell, 1991), sequencing and routing (Caron et al., 1998; Goetschalckx and Donald Ratliff, 1988; Ratliff and Rosenthal, 1983), and batching (Elsayed, 1981; Rosenwein, 1996). This research has also looked at picking policies (parallel, zone, and dynamic zone) and concluded that the effectiveness of order picking policy depends heavily on the properties of the particular warehouse (e.g., warehouse shape, type of storage rack, product type and size, and required throughput) (Hsieh and Tsai, 2006; Hwang and Cho, 2006; Petersen, 2004; Yu, 2008). Based on the results of these studies, warehouse managers have been able to make better decisions about which order picking system to implement to improve performance and decrease operating costs. However, there is still room for improvement. For instance, although humans make the picks in these systems, the influence of the picker has generally been ignored. Work elements of an order picker in a low-level picker-to-parts system include tasks such as traveling to pick locations (about $50 \%$ of a picker's time), searching for pick locations (about $20 \%$ of a picker's time), and picking the items (about 15\% of a picker's time) (Tompkins, 2010). Setting up the order that has to be picked or starting to pick again after short interruptions is also time consuming (Schultz et al., 2003). The effort, motivation and actions of individual pickers are important factors that influence the performance of manual order picking systems. Consequently, these behavioral aspects need to be included in research on order picking performance. Furthermore, optimizing order picking performance is typically operationalized as minimizing the time it takes to complete orders with a minimum number of picking errors. 
In the current study, we focus on this influence of the order picker by keeping factors such as the picking area, product layout, and sequencing constant, and by investigating behavioral factors that influence a picker's performance in terms of productivity and quality. More specifically we emphasize two elements that may facilitate optimizing performance given a certain picking policy: Incentive systems and picker regulatory focus. Next, we discuss the literature on incentive systems and hypothesize which incentive system is most effective under which picking policy. Then we move to picker characteristics in terms of regulatory focus and discuss how this affects the influence of the incentive system.

\section{$\underline{2.2 \text { Incentive systems }}$}

Awarding financial incentives to reward performance is a common method to align the efforts of employees with the objectives of the company and to improve productivity and quality (GomezMeja and Balkin, 1989). Previous studies have emphasized that financial incentives are among the most important drivers of employee performance (Jenkins and Gupta, 1981; Jenkins Jr et al., 1998; Locke et al., 1981, 1980). Although some studies argue that offering external rewards such as money undermines intrinsic motivation (Eisenberger and Cameron, 1996; Kohn, 1993a, 1993b), a meta-analysis of 39 studies by Jenkins Jr et al. (1998) showed a substantial corrected correlation of .34 between financial incentives and performance quantity.

One of the most important considerations in implementing incentive systems is whether the organization should implement an incentive system that is completely based on individual performance, or rather adopt a cooperation-based reward scheme in which the group performance determines at least part of the individual pay. Working in teams is increasingly prevalent in modern organizations, and individual incentive systems do not always fit well in that context (Zingheim and Schuster, 2000). Employees often have to execute interdependent tasks, and it can be difficult for a manager to evaluate the performance of an employee without considering the influence of direct colleagues (Dobbins et al., 1991). The choice for either individual or team focused incentive systems is implicitly also the choice between highlighting the importance of either competition or cooperation among employees (Tjosvold, 1986). Whereas individual incentives can be expected to reinforce individual performance, team incentives may stimulate more cooperative behavior at group level (DeMatteo et al., 1998).

Several pitfalls exist for both competitive and cooperative reward systems for teamwork. If a group works with a very strongly emphasized competitive reward scheme, the stability and 
cohesion of the group might be put at risk, even with independent tasks. This could lead to a polarization of effort levels with some people working slightly harder, but many demotivated people working substantially slower, resulting in a negative overall effect (Dickinson and Isaac, 1998). If a group works with a very cooperation-oriented incentive scheme, social loafing and free riding are common problems. These phenomena can occur if individuals do not perceive that the outcome of the group process is influenced by their efforts, resulting in low motivation to contribute to the group. This problem is not likely to exist if the efforts of the individual group members are indispensable (Shepperd, 1993).

The exact circumstances under which cooperative incentives are more effective than competitive incentives are unclear, but task interdependence has been identified as one of the most critical factors influencing the effectiveness of team rewards (Wageman and Baker, 1997). Task interdependence refers to the degree of interaction and cooperation between team members that is required to complete a specific task (Sundstrom et al., 1990). The literature on the topic has consistently demonstrated that matching tasks and rewards lead to higher performance. This implies that it is more effective to use competitive incentives for independent tasks, and cooperative incentives for interdependent tasks.

If these findings are translated to the context of order picking, we can hypothesize which incentive system leads to better performance when used in combination with a particular order picking method. For example, a parallel picking system entails a relatively low degree of interdependence. Pickers work individually on a task, and are not required to communicate and coordinate work with other pickers. They know that they are responsible for their own performance, and are likely most motivated if the incentive system fits these circumstances, i.e. under a competitive incentive system. An increase in motivation at work has commonly been linked to a variety of positive outcomes. Not only are motivated employees more productive, they most likely also work more precisely, and are more satisfied about their job (Kanfer et al., 2008). Therefore, a competitive incentive system is expected to perform especially well in the context of parallel picking, which is stated in the first hypotheses.

Hypothesis 1a: In parallel picking, a competition-based incentive system will result in higher productivity than a cooperation-based incentive system. 
Hypothesis 1b: In parallel picking, a competition-based incentive system will result in higher quality than a cooperation-based incentive system.

In a zone picking system, pickers work in a team. Each picker only finishes part of an order and as a consequence the throughput time of an order is dependent on the performance of each individual picker. Moreover, in a situation with limited buffers, the maximum work speed of a worker in a later zone is serially dependent on the on the speed of the workers in the earlier zones (Schultz et al., 1999). Thus, zone picking is associated with a high degree of task interdependency. Since high levels of task interdependency are a facilitator of the motivating effects of a group incentive system, pickers will probably be more motivated at work if the incentive system is group oriented to a certain extent as well. Since motivation should influence productivity and quality, it follows that the productivity performance and quality performance of pickers working with a zone picking method are higher under an incentive system that focuses more on cooperation.

Hypothesis 2a: In zone picking, a cooperation-based incentive system will result in higher productivity than a competition-based incentive system.

Hypothesis 2b: In zone picking, a cooperation-based incentive system will result in higher quality than a competition-based incentive system.

Dynamic zone picking is -to some degree- a combination of parallel picking (since the individual performance of pickers determines where they hand over products to other pickers) and zone picking (with flexible zone boundaries). In other words dynamic zone picking includes both task elements that are independent in nature as well as task elements that are interdependent in nature. As a consequence we expect multiple effects in dynamic zone picking. On the one hand, the independent aspect of dynamic zone picking calls for a competition-based reward system. On the other hand, the cooperative aspect would better be served by a cooperation-based incentive system. The net effect of the two counteracting mechanisms is unknown, and we have no theoretical grounds to make sensible predictions about this.

\subsection{Regulatory focus}

In addition to incentive systems we also focus on individual characteristics of pickers. To gain more insight into this issue we employ regulatory focus theory. This theory, first coined by Higgins 
(1997, 1998), is based in psychology and is well-suited to be employed in investigating any type of motivation that drives people to achieve certain goals (Higgins, 1998). It can be described as a mindset that influences how people think and act. Regulatory focus theory distinguishes between two self-regulatory strategies that influence behavior. A promotion focus emphasizes accomplishing desired, attractive, and positive goals and aims at achievement, growth, and advancement. A prevention focus emphasizes fulfilling duties, responsibilities, and obligations, and includes an element of fear of failing (Higgins, 1998). Also, prevention-focused people are often more riskaverse than promotion-focused people (Halvorson and Higgins, 2013). In contrast with personality theories and measures such as the Big Five (Digman, 1990), regulatory focus theory has been more directly linked to behavior. Some studies even suggest that the relationship between personality traits and individual behavior is actually mediated by the regulatory focus of individuals (Lanaj et al., 2012). Since incentive systems are aimed at influencing the motivation and behavior of workers, regulatory focus is a relevant construct to investigate in the context of this study. Although promotion and prevention focus are two theoretically distinct constructs, several studies suggest that an emphasis of one type of regulatory focus mitigates the effects of the other type (Shah and Higgins, 2001; Zhou and Pham, 2004). For example, a person with a dominant promotion focus is unlikely to be partly guided by a prevention focus at the same time. Because of this, we follow Lockwood et al. (2002) in expecting that the dominant regulatory focus of order pickers influences performance, rather than the individual effects of both regulatory foci.

In the context of order picking performance, we expect that the influence of each of the two regulatory foci partly depends on the type of performance. Prevention-focused people tend to follow rules and regulations conscientiously and to avoid errors (Higgins, 1997; Wallace et al., 2009), which suggests that they could make fewer picking errors. A promotion focus, on the other hand, has been linked to production performance (Wallace et al., 2009, 2008) and to sensitivity to the presence or absence of rewards (Kark and Van Dijk, 2007). However, these results are not generally applicable, and are subject to a very influential factor: the fit between people's regulatory focus and the goal that they have to pursue (Higgins, 2000). For example, Shah et al. (1998) showed that more promotion-focused people performed substantially better in an anagram task if the briefing and task itself emphasized obtaining gains rather than avoiding losses. The results were reversed for prevention-focused people. This finding supports the expectation that regulatory fit leads to a higher motivation and performance, and that people are more sensitive to information 
congruent with their dominant regulatory focus. Regulatory fit has also been linked to a higher task enjoyment (Freitas and Higgins, 2002), an outcome that is only a small step away from job satisfaction. Similarly, whether a task is executed individually or in a team also has a different effect on people with a different regulatory focus. Lee et al. (2000) showed that promotion-focused people rated individual events as more important than prevention-focused individuals, whereas the situation is exactly the opposite for team events. The same holds for the rewards structure. In an experiment, Beersma et al. (2013) showed that more prevention-focused teams were more engaged and performed better with a cooperation-based incentive system than with an individual-based incentive system while the reverse was true for promotion-focused teams.

Based on these findings we argue that the fit of the picking method and the incentive system is especially beneficial if it also fits the regulatory focus of the picker. For example, the hypothesized better performance of parallel picking with a competition-based incentive system is expected to hold especially for more promotion-focused pickers, who generally place more emphasis on their own achievements and potential positive outcomes and thus are especially motivated by an individually oriented task and incentive system. In contrast, this method and this incentive scheme are expected to be a worse fit for more prevention-focused pickers. This is reflected in hypotheses $3 \mathrm{a}$ and $3 \mathrm{~b}$.

Hypothesis 3a: In parallel picking, pickers with a dominant promotion focus will perform better in terms of productivity with a competition-based incentive system than with a cooperation-based incentive system, while no such difference exists for pickers with a dominant prevention focus.

Hypothesis 3b: In parallel picking, pickers with a dominant promotion focus will perform better in terms of quality with a competition-based incentive system than with a cooperation-based incentive system, while no such difference exists for pickers with a dominant prevention focus.

Zone picking and a cooperation-based incentive system, on the other hand, is a good combination especially for more prevention-focused pickers, who place more emphasis on team performance as we expect them to be especially motivated by a group-oriented task and incentive scheme. This combination is likely not so suitable for more promotion-focused pickers, who emphasize individual performance. Thus the difference between a cooperation-based incentive system and a competition-based incentive system in zone picking is therefore most likely larger for 
prevention-focused pickers, while the incentive system is not expected to make a substantial difference for more promotion-focused pickers in zone picking. This leads to hypotheses $4 \mathrm{a}$ and $4 \mathrm{~b}$.

Hypothesis 4a: In zone picking, pickers with a dominant prevention focus will perform better in terms of productivity with a cooperation-based incentive system than with a competition-based incentive system, while no such difference exists for people with a dominant promotion focus.

Hypothesis 4b: In zone picking, pickers with a dominant prevention focus will perform better in terms of quality with a cooperation-based incentive system than with a competition-based incentive system, while no such difference exists for people with a dominant promotion focus.

Dynamic zone picking is a mix of an individual and team picking method. Theoretically it should be more productive than regular zone picking, assuming that the work rate of the pickers is stationary and not affected by the requirement to coordinate where an order should be passed on. However, Doerr et al. (2004) found that a dynamic zone policy at an experimental production line did not outperform a fixed zone policy, partly as a consequence of higher worker heterogeneity and worker variability. This result suggests that individual differences between workers influence how motivated they are on a task that is not a characterized by a mix of independent and interdependent work.

We argued earlier that both competition-based incentive schemes and cooperation-based incentive schemes could be motivating in dynamic zone picking. Here we extend this reasoning by posing that the dominant regulatory focus of the pickers may determine which aspect of the task (teamwork or individual work) is the most salient and hence which incentive scheme would be more motivating with a dynamic zone picking method. Lee et al. (2000) used an experimental approach to find that when a prevention focus is salient in independent tasks, individuals rate events with interdependent (team) outcomes as more important than independent (individual) outcomes. Exactly the opposite pattern emerged with a salient promotion focus. It is likely that people are more motivated to work hard to achieve an outcome that they perceive as being important. Therefore, we also expect that for pickers with a dominant prevention focus the interdependent aspects of dynamic zone picking would be highly salient and consequently that a cooperative incentive scheme would be more motivating than a competitive incentive scheme. In reverse, we expect that for pickers with a dominant promotion focus the independent aspects of dynamic zone 
picking would be highly salient and consequently that an individual incentive scheme would be more motivating than a group incentive scheme. This leads to hypothesis $5 \mathrm{a}$ and $5 \mathrm{~b}$.

Hypothesis 5a: In dynamic zone picking, promotion-focused pickers will perform substantially better in terms of productivity with a competition-based incentive system than with a cooperationbased incentive system, whereas prevention-focused pickers will perform substantially better with a cooperation-based incentive system than with a competition-based incentive system.

Hypothesis 5b: In dynamic zone picking, promotion-focused pickers will perform substantially better in terms of quality with a competition-based incentive system than with a cooperation-based incentive system, whereas prevention-focused pickers will perform substantially better with a cooperation-based incentive system than with a competition-based incentive system.

\section{Methodology}

The following section describes the participants, the procedure, and the manipulations and measures used in the experiment.

\subsection{Participants}

The hypotheses were tested using data obtained from an experiment with 142 participants arranged into 48 three-person teams. Additionally, for each experimental session there was also a quality inspector, whose sole task was to check the work of the three pickers. The role of quality inspector was normally performed by people who subscribed to participate to the experiment, but a confederate of the experimenter worked as quality inspector in 8 teams because only three people had subscribed to the particular timeslots. Whether a participant or a confederate served as quality inspector had no noticeable impact on the performance outcomes of the team. In two teams, a confederate of the experimenter worked as order picker to substitute for last minute cancellations of participants. The results of these pickers were not taken into consideration. Of the 142 participants, $28(20 \%)$ were university students studying business, 39 (27\%) were professional warehouse employees, and 75 (53\%) were logistics students at a vocational college, training to become future warehouse employees.

The university students were recruited through notifications on the university's intranet,

and through emails to all students in various courses. Regardless of performance and incentive 
condition, each student received $€ 20$ in exchange for their participation. The professional order pickers were recruited through a recruitment agency and through contacting various companies active in the Dutch warehousing sector. Ten companies provided at least one participating team of order pickers. The professional pickers also received $€ 20$ for their participation, regardless of how they performed. Of the 142 participants $76.8 \%$ were male, $51.1 \%$ were aged between 16 and 20 , $24.8 \%$ aged between 21 and 25 , and $24.1 \%$ aged between 26 and 48 . Of the 142 pickers, $63.4 \%$ of the participants did not have any order picking experience, whereas $16.2 \%$ had worked as order pickers for at least one year. Most participants (69.7\%) were Dutch native speakers and completed the questionnaires in Dutch. Of the remaining participants, $14.1 \%$ filled out English questionnaires and $16.2 \%$ completed Polish questionnaires. The Polish respondents were all warehouse professionals.

\section{$\underline{3.2 \text { Procedure }}$}

The experiment took place in an experimental warehouse setup (Figure 1). This warehouse was especially erected with the support of several material handling suppliers, supplying racks, picking carts, labels, dummy products, and a Warehouse Management System (WMS). This approach was chosen because order picking is a task that is difficult to replicate realistically (in terms of travel distances, layout, picking heights, product sizes and weights, professional full-size equipment) in a regular laboratory environment, and laboratory experiments can therefore suffer from generalization issues: results obtained in the lab could be unrepresentative for what happens in practice. A field experiment combines the manipulation of independent variables and random assignment to conditions in a completely controlled setting with an environment and task that are highly similar to order picking in practice. This approach should provide findings that are not only obtained through a methodologically rigorous approach, but also are highly generalizable to practice. 

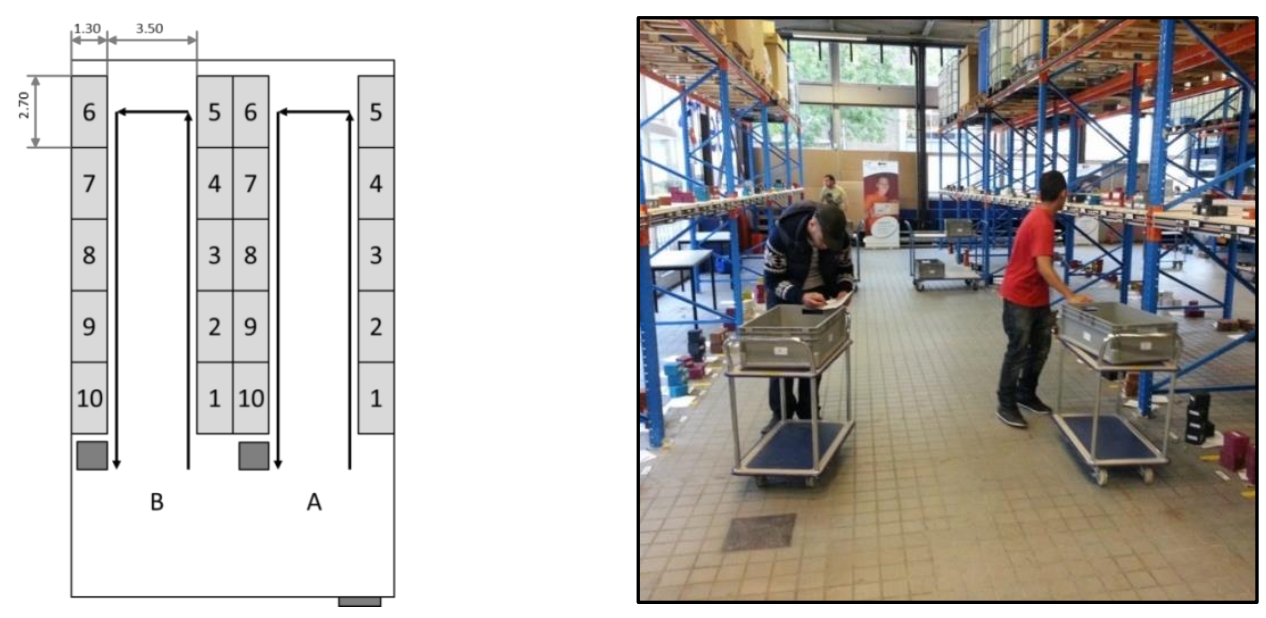

Figure 1: Experimental warehouse layout (measures are in meters)

The 1000 colored and labeled wooden dummy products ranging in volume from 0.2 to 2 liters and in weight from $50 \mathrm{~g}$ to $500 \mathrm{~g}$ were placed at two sides of two (identical) warehouse aisles. The two identical aisles allowed us to execute two simultaneous experimental sessions. The aisles were divided in 10 sections, each containing 5 locations with 2 levels. The locations were logically numbered. For example location A05.3.1 meant that the product was stored in aisle A, in section 5, at location 3 on the lower level. Participants used picking carts to transport the crates (one crate per order). After filling out a pre-questionnaire containing questions on demographic information and regulatory focus, the pickers did a practice round of an order picking task in which they had to pick as many orders with as few errors as possible in 10 minutes, while using a particular method, and subject to a particular incentive structure. On average, the orders contained 8.38 order lines $(\sigma=2.35, \log$-normally distributed) and each order line prescribed the picking of one or two units $(\mu=1.5)$ of a particular product. The pickers had to pick the quantity of the correct product, and mark the picking list once a line was picked. Each team worked with the same set of orders. The experimenter used a stopwatch to record start and finish times of each order. When an order was completed, the quality inspector checked whether the pickers had made any mistakes (wrong quantity, wrong product, etc.). The pickers were told that their performance was being tightly monitored by an additional check by one of the experimenters. After a short break, the participants helped to replace the dummy products in their original location. Subsequently, the 'real' run of the same task started, also lasting 10 minutes. In zone picking, the participants were assigned to a zone-based on their speed in the practice run: the fastest picker in the first zone, the second-fastest picker in the second zone, and the slowest picker in the last zone. This ensured that all pickers 
could reach their full performance potential. Furthermore, even though in zone picking pickers work in separate zones, helping each other was still possible to a certain extent, for example by neatly sorting the products in the crate, or by pointing out where a colleague had to make the next pick. Participants completed a post-questionnaire before the end of the experiment. The experiment ended after the dummy products had been replaced and after a short debriefing. The total duration was approximately one hour per group. The experiment was part of an experimental session lasting two hours in total, but all data used for this paper were obtained in the first hour.

\section{$\underline{3.3 \text { Manipulations \& Measures }}$}

The experiment used a $3 \times 2$ between-subjects design, with picking method and incentive condition as independent variables. Picker teams were randomly assigned to a picking method and incentive condition.

Picking methods: We used three paper picking methods: 47 participants used parallel picking, 47 used zone picking, and 48 employed dynamic zone picking. The zones used for zone picking are shown in Figure 1, with section 1-3 as part of zone one, section 4-7 as part of zone two and section 8-10 as part of zone three. The zones were delimited by a table that served as a buffer. The second zone consisted of four sections, whereas the first and third zone only consisted of three sections. This setup was chosen based on several pilot sessions to balance the workload of all pickers by compensating for the potential shortcut in the U-shape that the second picker could take if no products had to be picked in section 5 or 6 . We controlled for this in the analyses.

Motivational incentives: Sixty-nine participants (distributed across the three methods), had to complete as many orders as possible without making errors in a team (cooperation-based incentive system). They were told that if the performance of their entire team as a whole was the best among all participating teams they would each get a bonus, thus creating cooperation. The other 73 participants had to complete as many orders as possible without making mistakes individually (competition-based incentive system). They were told that if the individual performance of a team member was amongst the best four of all participating individuals, he or she would get a personal bonus, thus creating competition. In both conditions, the winners (all four members of the best performing team, and the four best performing individual pickers) received a $€ 100$ voucher for a large electronics \& media retailer. The distribution of participants across backgrounds, picking methods and incentive conditions is displayed in Table 1. 
Productivity was measured by counting the amount of completed order lines per individual during the real picking run of 10 minutes, ensuring that the pickers had already become familiar with the method in the practice round.

Quality was measured by the percentage of orders per individual that contained errors during the real picking round. This measure was preferred to the percentage of individual order lines that contained errors to prevent an inflation of the error percentage (because of stacking error on error in a single order). In zone and dynamic zone picking, an error in an early zone sometimes causes unavoidable errors in later zones, and these errors are not interesting for the current study. The quality inspector of each team checked whether each order contained the right types and numbers of products. We told the quality inspectors that their accuracy would contribute to the group performance, and that the experimenters would randomly double-check the quality for approximately $25 \%$ of the orders. The checks revealed that the quality inspectors hardly made any mistakes.

Table 1: Participants per background, picking method, and incentive condition

\begin{tabular}{|c|c|c|c|c|c|c|c|c|c|}
\hline \multirow[b]{3}{*}{ Background } & \multirow[b]{3}{*}{ Incentive } & \multicolumn{8}{|c|}{ Picking Method } \\
\hline & & \multicolumn{2}{|c|}{ Parallel } & \multicolumn{2}{|c|}{ Zone } & \multicolumn{2}{|c|}{ Dynamic } & \multicolumn{2}{|c|}{ Total } \\
\hline & & $\mathrm{N}$ & $\%$ & $\mathrm{~N}$ & $\%$ & $\mathrm{~N}$ & $\%$ & $\mathrm{~N}$ & $\%$ \\
\hline \multirow[t]{3}{*}{ University } & Team & 2 & $1.4 \%$ & 3 & $2.1 \%$ & 6 & $4.2 \%$ & 11 & $7.7 \%$ \\
\hline & Individual & 6 & $4.2 \%$ & 2 & $1.4 \%$ & 9 & $6.3 \%$ & 17 & $12.0 \%$ \\
\hline & Total & 8 & $5.6 \%$ & 5 & $3.5 \%$ & 15 & $10.6 \%$ & 28 & $19.7 \%$ \\
\hline \multirow[t]{3}{*}{ Professional } & Team & 6 & $4.2 \%$ & 6 & $4.2 \%$ & 6 & $4.2 \%$ & 18 & $12.7 \%$ \\
\hline & Individual & 6 & $4.2 \%$ & 6 & $4.2 \%$ & 9 & $6.3 \%$ & 21 & $14.8 \%$ \\
\hline & Total & 12 & $8.5 \%$ & 12 & $8.5 \%$ & 15 & $10.6 \%$ & 39 & $27.5 \%$ \\
\hline \multirow[t]{3}{*}{ Vocational } & Team & 12 & $8.5 \%$ & 15 & $10.6 \%$ & 12 & $8.5 \%$ & 39 & $27.5 \%$ \\
\hline & Individual & 15 & $10.6 \%$ & 15 & $10.6 \%$ & 6 & $4.2 \%$ & 36 & $25.4 \%$ \\
\hline & Total & 27 & $19.0 \%$ & 30 & $21.1 \%$ & 18 & $12.7 \%$ & 75 & $52.8 \%$ \\
\hline \multirow[t]{3}{*}{ Total } & Team & 20 & $14.1 \%$ & 24 & $16.9 \%$ & 24 & $16.9 \%$ & 68 & $47.9 \%$ \\
\hline & Individual & 27 & $19.0 \%$ & 23 & $16.2 \%$ & 24 & $16.9 \%$ & 74 & $52.1 \%$ \\
\hline & Total & 47 & $33.1 \%$ & 47 & $33.1 \%$ & 48 & $33.8 \%$ & 142 & $100.0 \%$ \\
\hline
\end{tabular}

Promotion focus $(\alpha=.798)$ and prevention focus $(\alpha=.849)$ were measured using Wallace and Chen's (2006) Regulatory Focus at Work Scale in the first questionnaire that the participants completed. This scale has proven its validity and internal consistency in various work contexts (Wallace et al., 2009). A principal component analysis (PCA) with oblique (oblimin) rotation was conducted on the 12 items of the scale. The Kaiser-Meyer-Olkin measure showed an excellent fit 
$(\mathrm{KMO}=.872)$, and the KMO values for all individual items proved to be high $(>.77)$ as well. Bartlett's test of sphericity $\left(\chi^{2}(66)=677.4, p<.001\right)$ showed that the correlation matrix of the items is no identity matrix, which makes the items suitable for use in PCA. The scree plot confirmed that the twelve items are well represented by two components, jointly explaining $55.6 \%$ of the variance. Table 2 shows the structure and pattern matrix of the rotated factors. The clustering of the items revealed that factor 1 represents prevention focus, and factor 2 represents promotion focus. The prevention focus score of each participant was subtracted from his/her promotion focus score and the resulting difference score was standardized to arrive at a measure of the participant's dominant regulatory focus. This dominant regulatory focus is employed because, as explained in section 2.3, even though a single individual can theoretically to a certain extent be promotion and prevention focused at the same time, we believe that behavior is primarily guided by the focus that is most dominantly present (Lockwood et al., 2002). Subsequently a median split was performed to facilitate a direct comparison between participants with a dominant promotion focus and those with a dominant prevention focus.

In addition to participant background, age (in years), education (highest level completed), and experience with order picking (in months) of the participants were used as control variables. These controls differ significantly across background, but since we also control for participant background this does not influence the testing of our hypotheses. We also introduced a dummy variable indicating whether a participant was the second or third order picker in the zone or dynamic zone picking method. This was done to control for the different picking situations of the second and third picker, who are, to a certain extent, dependent on the first picker in these methods.

An adapted version of Hackman and Oldham's Job Diagnostic Survey (1974) was used to measure Job satisfaction $(\alpha=.805)$ of the participants. To make the scale more applicable to the context of the experiment, the word 'job' was replaced by the word 'task'. The items were rated using a five-point Likert scale ranging from 1 (strongly disagree) to 5 (strongly agree). The aggregate of the five items was standardized before being used as measure of job satisfaction. However, inspection of the participants' rating of their satisfaction with the tasks they performed did not reveal any noteworthy results. This could be attributable to the fact that participants only worked for a relatively short time, but it could also be the case that the employed scale was not thorough and extensive enough to draw conclusions about the effect of picking methods and incentive systems on job or task satisfaction. Therefore, we have only included the job satisfaction results in 
our correlation and overview tables (Table 3Table 4Table 6) for informative purposes, but not in the actual analyses.

The dominant regulatory focus questionnaire was translated to Dutch and Polish to ensure that non-native English speaking participants could understand all the questions. Ninety-nine participants filled out the Dutch version of the questionnaires, 23 completed the Polish version, and 20 filled out the English version. The reliability of the various scales proved to be $>.70$ for all languages. We used two-way analyses of covariance (ANCOVA) to examine whether differences in the outcome variables could be identified across the three languages, after controlling for method, incentive condition, age, education, participant background, and picking experience. We found no effect of language on either job satisfaction, $(F(2,123)=.739, p=.479)$, promotion focus $(F(2,117)=1.43, p=.242)$, or prevention focus $(F(2,118)=.427, p=.653)$. Therefore, the three different languages of the questionnaires will not be considered as a factor in the subsequent analyses.

Table 2: Regulatory focus at work scale (Wallace and Chen 2006) + pattern and structure matrix factor analysis (Oblimin rotation)

\begin{tabular}{lcccc}
\hline & \multicolumn{2}{c}{$\begin{array}{c}\text { Component 1 } \\
\text { (prevention) }\end{array}$} & \multicolumn{2}{c}{$\begin{array}{c}\text { Component 2 } \\
\text { (promotion) }\end{array}$} \\
\hline Items & Structure & Pattern & Structure & Pattern \\
\hline 4.1 Following rules and regulations at work & 0.66 & $\mathbf{0 . 5 6}$ & 0.49 & 0.21 \\
4.2 Completing work tasks correctly & 0.82 & $\mathbf{0 . 8 3}$ & 0.40 & -0.02 \\
4.3 Doing my duty at work & 0.82 & $\mathbf{0 . 8 3}$ & 0.41 & -0.01 \\
4.4 My work responsibilities & 0.78 & $\mathbf{0 . 8 4}$ & 0.32 & -0.10 \\
4.5 Fulfilling my work obligations & 0.84 & $\mathbf{0 . 8 3}$ & 0.44 & 0.02 \\
4.6 On the details of my work & 0.62 & $\mathbf{0 . 5 4}$ & 0.42 & 0.15 \\
4.7 Accomplishing a lot at work & 0.48 & 0.16 & 0.72 & $\mathbf{0 . 6 5}$ \\
4.8 Getting my work done no matter what & 0.21 & -0.17 & 0.68 & $\mathbf{0 . 7 6}$ \\
4.9 Getting a lot of work finished in a short amount of time & 0.38 & -0.05 & 0.83 & $\mathbf{0 . 8 5}$ \\
4.10 Work activities that allow me to get ahead at work & 0.45 & 0.16 & 0.65 & $\mathbf{0 . 5 7}$ \\
4.11 My work accomplishments & 0.46 & 0.22 & 0.59 & $\mathbf{0 . 4 8}$ \\
4.12 How many job tasks I can complete & 0.45 & 0.09 & 0.77 & $\mathbf{0 . 7 2}$ \\
\hline Eigenvalues & \multicolumn{2}{c}{5.26} & & 1.41 \\
\% of variance & 43.80 & & 11.80 \\
$\alpha$ & & 0.80 & & 0.85 \\
\hline
\end{tabular}

Note: Pattern loadings over .40 appear in bold 


\section{Analyses, results, and effect sizes}

\subsection{Analyses and results}

First, we used one-way analyses of variance (ANOVA) to check for differences in performance and dominant regulatory focus between the participants from different backgrounds (university, professional picker or vocational education). We found significant differences between backgrounds in order lines picked $(F(2,138)=4.279, p=.016)$. We also found a significant main effect of participant background in terms of percentage of orders with errors $(F(2,138)=5.55, p=.005)$. As can be seen in Table 3, the university students picked on average more order lines with a lower percentage of errors than the vocational students and professional order pickers. These results might seem surprising. However, it is important to realize that even though the professional order pickers are familiar with the concept of order picking and the structure of warehouse work, they are not necessarily familiar with the employed order picking method. Also, in some companies different paperless picking tools such as pick by voice or pick to light are used. It is very likely that many professionals mainly have experience with one particular picking method and tool, which differs from the task they had to perform in the experiment. Students on the other hand usually have no experience with order picking, but are generally relatively intelligent and able to learn quickly. General cognitive ability has been demonstrated to be an important predictor of performance in many different types of jobs (Ree et al., 1994). This could potentially explain the fact that students were on average slightly more productive and accurate than professional pickers. We found that the different backgrounds differed in dominant regulatory focus $(F(2,131)=3.156$, $p=.046)$. To account for the differences between the groups found in these preliminary analyses, we included participant background as a fixed control factor (using dummy variables) in the relevant subsequent analyses.

Table 3: Means and Standard Deviations per Participant Background

\begin{tabular}{|c|c|c|c|c|c|c|c|c|}
\hline & \multicolumn{8}{|c|}{ Background Type } \\
\hline & \multicolumn{2}{|c|}{ University } & \multicolumn{2}{|c|}{ Professional } & \multicolumn{2}{|c|}{ Vocational } & \multicolumn{2}{|c|}{ Total } \\
\hline & Mean & Std. Dev. & Mean & Std. Dev. & Mean & Std. Dev. & Mean & Std. Dev. \\
\hline Lines & 51.36 & 14.61 & 45.95 & 12.44 & 41.40 & 17.39 & 44.68 & 15.97 \\
\hline Errors & 0.12 & 0.17 & 0.31 & 0.33 & 0.18 & 0.20 & 0.21 & 0.25 \\
\hline Job sat. & 0.06 & 0.87 & 0.06 & 0.99 & -0.05 & 1.06 & 0.00 & 1.00 \\
\hline Dom. RF & 0.22 & 1.03 & -0.34 & 0.98 & 0.10 & 0.97 & 0.00 & 1.00 \\
\hline Experience & 0.14 & 0.76 & 30.51 & 49.31 & 3.71 & 8.35 & 10.37 & 29.13 \\
\hline Education & 2.32 & 1.33 & 2.87 & 0.92 & 2.33 & 0.59 & 2.49 & 0.91 \\
\hline Age & 19.23 & 2.09 & 32.77 & 8.54 & 19.89 & 3.46 & 23.32 & 7.83 \\
\hline
\end{tabular}


Lines $=$ error-free order lines picked, errors $=\%$ orders with error(s), Job sat. $=$ Job satisfaction, Dom. $\mathrm{RF}=$ Dominant regulatory focus (higher $=$ more promotion focus, lower $=$ more prevention focus)

Subsequently, we examined the descriptive statistics of the key variables. Table 4 shows significant correlations of education with dominant regulatory focus and age, and of age with the percentage of orders with errors and with order picking experience. These correlations suggest that it is important to control for age, education and order picking experience in the analyses. However, they do not reveal information that could be used to answer our hypotheses.

Table 4: Means, standard deviations, and correlations between key variables

\begin{tabular}{|c|c|c|c|c|c|c|c|c|c|}
\hline & Variable & Mean & Std. dev. & 1 & 2 & 3 & 4 & 5 & 6 \\
\hline 1 & Error-free order lines picked & 44.7 & 16.0 & - & & & & & \\
\hline 2 & $\%$ orders with errors & 20.5 & 24.9 & .15 & - & & & & \\
\hline 3 & Job sat. & 0.0 & 1.0 & -.12 & -.03 & .81 & & & \\
\hline 4 & Dom. RF & 0.0 & 1.0 & .01 & -.08 & .01 & - & & \\
\hline 5 & Age (years) & 23.3 & 7.8 & .10 & $.20 *$ & -.01 & -.12 & - & \\
\hline 6 & Education (levels 1-5) & 2.5 & 0.9 & -.06 & .09 & -.10 & $-.23 * *$ & $.20 * *$ & - \\
\hline 7 & Experience (months) & 10.4 & 29.1 & -.02 & .12 & .06 & -.18 & $.60 * *$ & .06 \\
\hline
\end{tabular}

$* p<.05$

$* * p<.01$

Job sat. $=$ Job satisfaction, Dom. $\mathrm{RF}=$ Dominant regulatory focus (higher $=$ more promotion focus, lower $=$ more prevention focus). Cronbach's $\alpha$ is displayed in italics on the diagonal of the job satisfaction variable.

Note: $N=142$. Pairwise deletion of missing values employed, resulting in a lower $N$ for some correlations.

As a next step in the analysis, we investigated how much of the variance in the outcome variables could be explained by the team-level and how much is attributable to the aggregation of the data of individual team members. In our case the team-level refers to the level of the 48 three-person picking teams that participated in the study. This analysis was performed according to the steps explained by Bliese (2009), using the multilevel package within R 3.0.1 (R Core Team, 2013).

Table 5: Group-level properties

\begin{tabular}{lllll}
\hline & ICC(1) & ICC(2) & RGR z-value & $\begin{array}{l}\text { RGR p-value } \\
\text { (one tailed) }\end{array}$ \\
\hline 1. Error-free order lines picked & 0.30 & 0.54 & -1.83 & .034 \\
2. \% orders with errors & 0.13 & 0.29 & -0.44 & 0.33 \\
\hline
\end{tabular}

First, we calculated the intraclass correlation coefficients $\operatorname{ICC}(1)$ and $\operatorname{ICC}(2)$ of the order lines picked and the percentage of orders with errors. The ICC(1) values indicate to what extent the variance in the outcome variable can be explained by group membership, and the ICC(2) values indicate the extent (with 1 being completely) to which the groups can be reliably differentiated in 
terms of the outcome variables (Bliese, 2009). We employed Random Group Resampling (RGR) to find out whether the within-group variance of the actual groups differed from the variance of 960 pseudo groups that are of identical size as the original groups (Table 5). RGR allowed us to determine whether the relationships at group level can really be attributed to the groups (group effects), or simply represent individual data that are aggregated to the group level (grouping effects) (Bliese and Halverson, 2002). ICC is defined as a non-negative parameter, but Bliese and Halverson's (1998) ICC(1) formula can assume negative values if the differences within the groups are substantially larger than the differences between the groups (Shieh, 2012). Group membership explained at least part of the variance for the percentage of orders with errors and especially for the number of order lines picked. The RGR results showed that the within-group variances of the real groups were significantly smaller than the within-group variances of the pseudo-groups for the number of order lines picked. This implies that part of the individual picking performance is explained by the team to which a participant belongs. Based on these results, we included random intercepts to test for multilevel effects in the models explaining the number of order lines picked and the percentage of orders with errors.

Before creating the different models to predict picking performance, the different types of performance were averaged per incentive condition and picking method to get a general insight in the data. Table 6 suggests that the number of lines picked does not differ substantially across methods in the cooperation-based incentive condition, but that these differences are much larger in the individual incentive condition. This suggests that an interaction effect between picking method and incentive condition could be present.

Productivity: Before adding the control and independent variables to a model predicting productivity, we compared a model without a random intercept with one that contained a random, group dependent intercept. These models were fit using the 'lme' and the 'gls' functions in the 'nlme' package (Pinheiro et al., 2013) in R 3.0.1 (R Core Team, 2013). The categorical variables (participant background, picking method, incentive condition, and dominant regulatory focus) were treated as N-1 dummy codes in the model matrix to be included in the model. The $-2 \log$ likelihood value for the random intercept model (996.45) appeared significantly larger than the value for the model without the random intercept $(986.59, \Delta=9.86, p<.01)$, indicating a significantly better fit for the random intercept model. Subsequently, we created a linear mixed-effects 
model with a random intercept and participant background, age, education, and order picking experience as control variables. Furthermore, we controlled for the position of the pickers in a zone or dynamic zone picking method. In the first model, displayed in Table 7, the picking method was added to the control variables as predictor. The effect of the picking method on the number of lines picked was significant, which indicates that the employed picking method significantly influences the number of lines picked.

Table 6: Means and Standard Deviations per Method and Incentive Condition

\begin{tabular}{|c|c|c|c|c|c|c|c|}
\hline \multirow{3}{*}{ Picking Method } & & \multicolumn{6}{|c|}{ Incentive Condition } \\
\hline & & \multicolumn{3}{|c|}{ Team } & \multirow{2}{*}{$\begin{array}{c}\text { Individual } \\
\text { Std. } \\
\text { Dev. }\end{array}$} & \multicolumn{2}{|c|}{ Total } \\
\hline & & Mean & $\begin{array}{l}\text { Std. } \\
\text { Dev. }\end{array}$ & Mean & & Mean & $\begin{array}{l}\text { Std. } \\
\text { Dev. }\end{array}$ \\
\hline \multirow{3}{*}{ Parallel } & Lines & 45.94 & 17.95 & 54.56 & 13.22 & 51.23 & 15.61 \\
\hline & Errors & 0.23 & 0.25 & 0.25 & 0.28 & 0.24 & 0.26 \\
\hline & Job sat. & 0.10 & 1.10 & 0.25 & 1.09 & 0.18 & 1.08 \\
\hline \multirow{3}{*}{ Zone } & Lines & 45.21 & 19.07 & 33.91 & 11.85 & 39.68 & 16.78 \\
\hline & Errors & 0.21 & 0.30 & 0.18 & 0.25 & 0.19 & 0.27 \\
\hline & Job sat. & -0.17 & 0.97 & 0.23 & 0.83 & 0.03 & 0.92 \\
\hline \multirow{3}{*}{ Dynamic } & Lines & 45.83 & 15.79 & 41.33 & 10.81 & 43.58 & 13.58 \\
\hline & Errors & 0.14 & 0.17 & 0.23 & 0.23 & 0.18 & 0.21 \\
\hline & Job sat. & -0.41 & 0.93 & 0.00 & 0.99 & -0.20 & 0.98 \\
\hline \multirow{3}{*}{ Total } & Lines & 45.63 & 17.35 & 43.85 & 14.73 & 44.68 & 15.97 \\
\hline & Errors & 0.19 & 0.24 & 0.22 & 0.25 & 0.21 & 0.25 \\
\hline & Job sat. & -0.18 & 1.01 & 0.16 & 0.97 & 0.00 & 1.00 \\
\hline
\end{tabular}

Lines $=$ picked order lines, Errors $=\%$ orders with error(s), Job sat. $=$ Job satisfaction

We employed the marginal and conditional $R^{2}$ as described by Nakagawa and Schielzeth (2013) to estimate the model fit. For this model, the fixed factors (allowed to vary per individual) explain $42 \%$ of the variance in productivity (marginal $R^{2}$ ), and the entire model (individual + group effects) explains $68 \%$ of the variance (conditional $R^{2}$ ). Table 6 shows that the average number of lines picked in the parallel picking method (mean $=51.23)$ is substantially higher than in the zone $($ mean $=39.68)$ and dynamic zone $($ mean $=43.58)$ methods. Pairwise comparisons to test these one-tailed directional hypotheses reveal that the productivity in parallel picking is indeed significantly higher than zone $(p=.01)$ and dynamic zone picking $(p=.032)$.

Table 7: Linear mixed-effects model. Dependent variable: order lines picked

\begin{tabular}{lcccccc}
\hline & \multicolumn{2}{c}{ Model 1 } & \multicolumn{2}{c}{ Model 2 } & \multicolumn{2}{c}{ Model 3 } \\
Effects & Wald $\chi^{2}$ & Df & Wald $\chi^{2}$ & Df & Wald $\chi^{2}$ & Df \\
\hline Random (group) intercept & $\mathbf{6 6 . 3}^{* *}$ & 1 & $\mathbf{4 4 . 6 8}^{* *}$ & 1 & 50.44 & 1 \\
Age & 2.15 & 1 & 1.70 & 1 & 0.41 & 1
\end{tabular}




\begin{tabular}{|c|c|c|c|c|c|c|}
\hline Participant background & $9.63 * *$ & 1 & $9.40 * *$ & 1 & 7.55 & 1 \\
\hline Picking experience & 1.97 & 1 & 0.98 & 1 & 0.08 & 1 \\
\hline Education & 1.12 & 1 & 1.08 & 1 & 0.40 & 1 \\
\hline Picking position 2 & $12.32 * *$ & 1 & $10.64 * *$ & 1 & 12.08 & 1 \\
\hline Picking position 3 & $24.60 * *$ & 1 & $25.76 * *$ & 1 & 24.15 & 1 \\
\hline Picking method & $7.68 *$ & 2 & 0.57 & 2 & 3.37 & 2 \\
\hline Incentive condition & & & 1.70 & 1 & 0.28 & 1 \\
\hline Method $\times$ condition & & & $6.65 *$ & 1 & 0.215 & 2 \\
\hline Dom. RF & & & & & $7.09 * *$ & 1 \\
\hline Method x Dom. RF & & & & & $8.13 *$ & 2 \\
\hline Condition $\times$ RF dominance & & & & & 6.78** & 1 \\
\hline Meth. $\times$ cond.$\times$ RF dom & & & & & $\mathbf{5 . 0 9} 9^{\dagger}$ & 2 \\
\hline Marginal $R^{2}$ & 0.42 & & 0.48 & & & \\
\hline Conditional $R^{2}$ & 0.68 & & 0.69 & & & \\
\hline \# of groups & 45 & & 45 & & & \\
\hline \# of individual observations & 119 & & 119 & & & \\
\hline
\end{tabular}

Dom. $\mathrm{RF}=$ Dominant regulatory focus (higher $=$ more promotion focus, lower $=$ more prevention focus)

$* * p<.01, * p<.05,{ }^{\dagger} p<.10$

To find out whether a competition or a cooperation-based incentive system leads to optimal picking performance, we added the incentive condition and its interaction with the picking method as predictors, resulting in Model 2 (Table 7). The interaction effect proved significant. Visualization of the interaction effect (Figure 2) and pairwise comparisons of the least-squares means (Lenth, 2013) showed that an individual-based incentive system yielded substantially more productivity in the parallel picking method $(\mathrm{M}=53.9, \mathrm{SD}=3.38)$ than a cooperation-based incentive system $(\mathrm{M}=46.84, \mathrm{SD}=4.52)$. In contrast, a cooperation-based incentive system performed better in a zone picking method $(\mathrm{M}=47.58, \mathrm{SD}=3.90)$ compared to a competition-based incentive system $(M=35.37, S D=3.41)$. Hardly any differences between a competition-based $(M=41.03$, $\mathrm{SD}=3.41)$ and cooperation-based $(\mathrm{M}=43.91, \mathrm{SD}=3.50)$ incentive system emerged for dynamic zone picking. These results support hypothesis $1 \mathrm{a}$ and $2 \mathrm{a}$.

The dominant regulatory focus, which indicates whether a participant is mainly preventionfocused or promotion-focused was added (Model 3, Table 7), predicting productivity in a threeway interaction to find out how regulatory focus interacts with the picking method and incentive condition. This interaction proved marginally significant (Wald $\chi^{2}=5.09, p=.078$ ). Inspection of the three-way interaction plots (Figure 3 ) reveals that participants with a dominant prevention focus consistently scored slightly higher with a cooperation-based incentive system, regardless of 
the picking method. In contrast, participants with a dominant promotion focus performed better in parallel picking with a competition-based incentive system and better in zone picking with a cooperation-based incentive system. No differences could be observed for a dynamic zone picking method. These results are not completely in line with hypotheses $3 \mathrm{a}$, 4a, and $5 \mathrm{a}$. Instead, the results suggest that pickers with a dominant promotion focus are more sensitive to the fit between the picking method and incentive system than pickers with a dominant prevention focus; a parallel picking method fits particularly well with an individual incentive system, whereas a zone picking method fits well with a team incentive system. A dynamic zone setup can be considered a combination of the other two methods, which is reflected by the similar performance in competitionbased and cooperation-based incentive conditions.

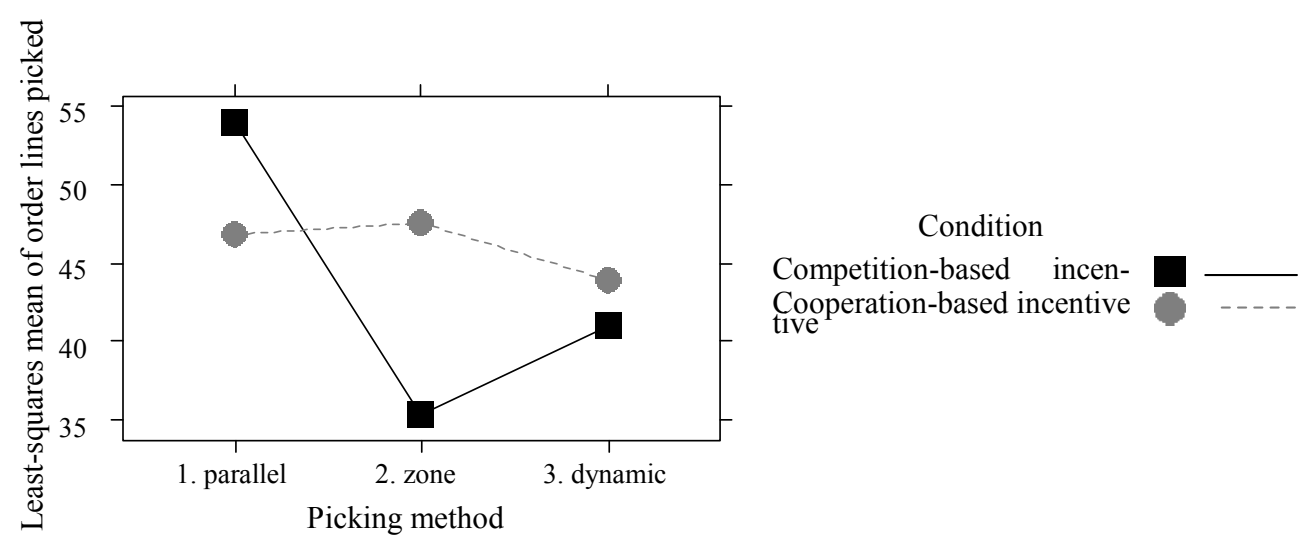

Figure 2: Interaction between picking method and incentive condition on productivity

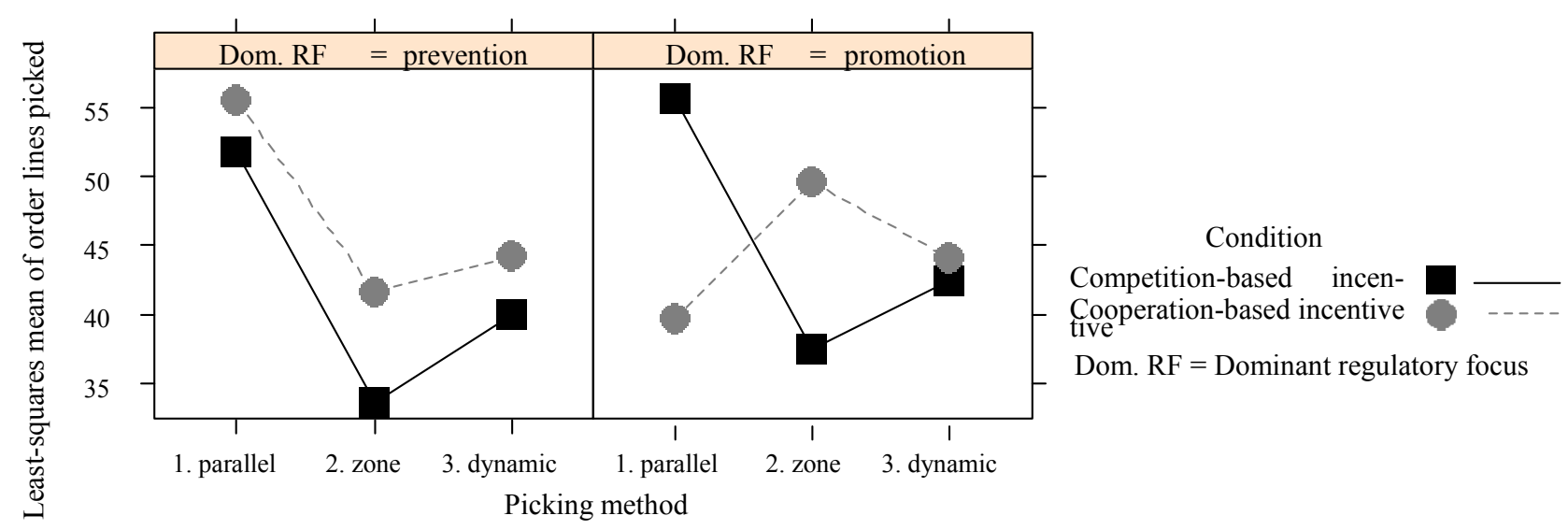

Figure 3: Three-way interaction between picking method, incentive condition and dominant regulatory focus on productivity 
Quality: With the number of orders with errors as dependent variable, the difference in -2 log likelihood value between the random intercept model (10.14) and the model without random intercept (9.68) was not significant ( $\Delta=0.47, p=.49$ ), which indicates that adding random intercepts did not significantly improve the model. Therefore, we performed a one-way ANCOVA on the number of orders containing errors, using method as factor and the same set of control variables as in the model that predicted productivity (Table 8). No significant main effect of method could be identified, and the model explained only $6.1 \%$ of the variance in errors (Model 1, Table 8). The interaction between picking method and incentive condition also proved to be significant for quality (Model 2, Table 8). The plot of the interaction effect (Figure 4) and the least-squares means show that the percentage of orders with errors is lower for a competition-based incentive system than for a cooperation-based incentive system in a parallel $(\mathrm{M}=18.3 \%, \mathrm{SD}=5.7 \%$ vs. $\mathrm{M}=23.2 \%$, $\mathrm{SD}=7.3 \%)$ and zone picking method $(\mathrm{M}=19.1 \%, \mathrm{SD}=5.3 \%$ vs. $\mathrm{M}=31.6 \%, \mathrm{SD}=6.5 \%)$, but higher in a dynamic zone picking method $(\mathrm{M}=29.6 \%, \mathrm{SD}=5.9 \%$ vs. $\mathrm{M}=14.4 \%, \mathrm{SD}=5.6 \%)$. The finding that pickers make less errors with competition-based incentives in parallel picking is in line with hypothesis 1b. However, even though we hypothesized that a zone picking system in combination with a cooperation-based incentive system would result in fewer errors (hypothesis $2 b)$, the opposite appears to be the case. The results suggest that people generally work more accurately when motivated by a competition-based incentive system, but that such a system leads to a higher number of errors if workers have to coordinate the distribution of tasks, which essentially happens in a dynamic zone picking method. There was no significant three-way interaction between the dominant regulatory focus of participants and the picking method or incentive condition (Model 3, Table 8), which implies hypotheses 3b, 4b, and 5b are not supported. Table 9 provides an overview of the results of the hypothesis testing performed based on the results of the experiment.

Table 8: One-way ANCOVA. Dependent variable: percentage of orders with errors

\begin{tabular}{lcccccc}
\hline \multirow{2}{*}{ Effects } & \multicolumn{2}{c}{ Model 1 } & \multicolumn{2}{c}{ Model 2 } & \multicolumn{2}{c}{ Model 3 } \\
& F & Df & F & Df & F & Df \\
\hline Fixed intercept & .179 & 1 & .099 & 1 & .099 & 1 \\
Age & 2.14 & 1 & 2.74 & 1 & $3.58^{\dagger}$ & 1 \\
Participant background & .123 & 1 & .430 & 1 & .162 & 1 \\
Picking experience & .015 & 1 & .051 & 1 & .276 & 1 \\
Education & .127 & 1 & .146 & 1 & .025 & 1
\end{tabular}


Picking position 2

Picking position 3

.000

2.39

.017

3.19

.156

2.21

.340

Incentive condition

3.25*

Method $\times$ condition

Dom. RF

Method x Dom. RF

1
2

2

Condition $\times$ Dom. RF

Meth. $\times$ cond. $\times$ Dom. RF

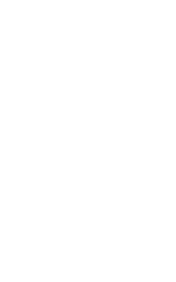

\begin{tabular}{lccc}
\hline$R^{2}$ & .061 & .101 & .191 \\
$\#$ of individual observations & 110 & 107 & 101 \\
\hline
\end{tabular}

Dom. $\mathrm{RF}=$ Dominant regulatory focus (higher $=$ more promotion focus, lower $=$ more prevention focus) $* * p<.01,{ }^{*} p<.05,{ }^{\dagger} p<.10$

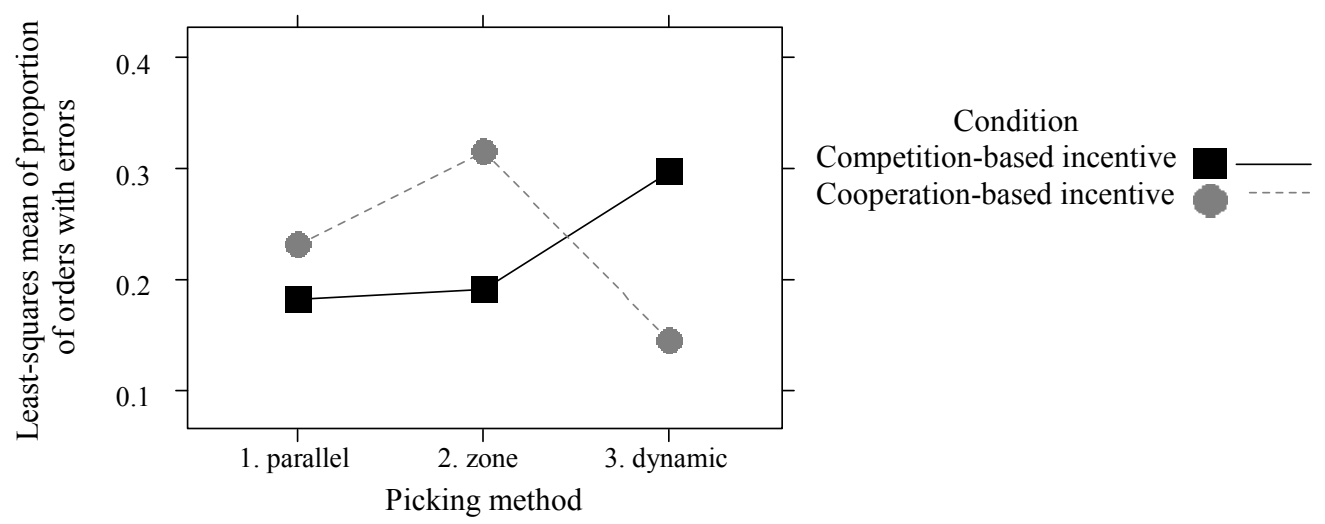

Figure 4: Interaction between picking method and incentive condition on quality 
Table 9: Overview of hypothesis testing results

\begin{tabular}{llll}
\hline Hypothesis & Supported? & Hypothesis & Supported? \\
\hline $1 \mathrm{a}$ & $\checkmark$ & $1 \mathrm{~b}$ & $\checkmark$ \\
$2 \mathrm{a}$ & $\checkmark$ & $2 \mathrm{~b}$ & $\times$ \\
3a & Partly & $3 \mathrm{~b}$ & $\times$ \\
4a & Partly & $4 \mathrm{~b}$ & $\times$ \\
$5 \mathrm{a}$ & Partly & $5 \mathrm{~b}$ & $\times$ \\
\hline
\end{tabular}

\subsection{Effect sizes}

Not only the statistical analyses and absolute numbers, but especially the effect sizes of the behavioral factors illustrate the impact that a change of incentive system or type of employee can have on productivity and quality in practice. Table 10 and Table 11 show performance improvements in a given picking method if the incentive system is changed or if pickers with a different dominant regulatory focus are deployed. Both above and below the dotted lines, the combination of method, incentive system, and possibly regulatory focus with the lowest performance in the particular performance measure is used as a baseline and is assigned a score of 100. Regarding quality, the highest number of errors is considered the lowest performance. The scores of the other combinations reveal their performance compared to the baseline. In the conclusion and discussion section, we provide more calculations to demonstrate the potential impact of employing the right incentive system and employees in particular situations.

Table 10: Comparison of effect sizes for parallel picking (Baseline $=100)$

\begin{tabular}{lcc}
\hline Parallel picking & Picked lines & Errors \\
\hline Cooperation-based incentive & $\mathbf{1 0 0}$ & $\mathbf{1 0 0}$ \\
Competition-based incentive & 115.2 & 79 \\
\hline Cooperation-based incentive, prom. dominance & $\mathbf{1 0 0}$ & $\mathbf{1 0 0}$ \\
Cooperation-based incentive, prev. dominance & 140.0 & 90.8 \\
Competition-based incentive, prom. dominance & 140.0 & 72.1 \\
Competition-based incentive, prev. dominance & 130.4 & 74.6 \\
\hline
\end{tabular}

Table 10 shows that in parallel picking the switch from a cooperation-based incentive system to a competition-based incentive system corresponds to $15.2 \%$ gains in productivity on average, whereas the number of errors simultaneously reduces by $21 \%$. If regulatory focus is also taken into consideration, the productivity benefits and reduction in errors could add up to $40 \%$ and $27.9 \%$ respectively. 
Table 11: Comparison of effect sizes for zone picking (Baseline $=100$ )

\begin{tabular}{lcc}
\hline Zone picking & Picked lines & Errors \\
\hline Cooperation-based incentive & 134.3 & $\mathbf{1 0 0}$ \\
Competition-based incentive & $\mathbf{1 0 0}$ & 60.7 \\
\hline Cooperation-based incentive, prom. dominance & 147.5 & 33.8 \\
Cooperation-based incentive, prev. dominance & 123.9 & $\mathbf{1 0 0}$ \\
Competition-based incentive, prom. dominance & 111.5 & 12.2 \\
Competition-based incentive, prev. dominance & $\mathbf{1 0 0}$ & 40 \\
\hline
\end{tabular}

In zone picking, the switch from a competition-based incentive system to a cooperationbased incentive system leads to $34.3 \%$ productivity gains on average. However, also the number of errors increases by 39.3 percentage points (Table 11). If regulatory focus is taken into account as well, productivity could increase by up to $47.5 \%$ whereas errors could simultaneously be reduced by up to 66.2 percentage points.

\section{Conclusion and discussion}

The importance of the order picking process in the supply chain emphasizes the need for research that optimizes this process. Whereas most of the literature on this topic focuses on aspects such as optimizing product-to-location assignment, picker zoning, order batching, and picker routing, this study contributes to the literature by demonstrating the influence of behavioral factors on order picking performance in a controlled field-experiment.

\subsection{Implications for practice}

In this study, we found that by optimally combining a given order picking method with either a cooperation-based or a competition-based incentive system can yield great benefits in terms of productivity and quality. Additional benefits can be reaped by assigning employees with a particular regulatory focus to a picking method and incentive system that best fits their regulatory focus. We provide an example of the potential impact of implementing these findings in practice, based on the data obtained in the experiment. Take a relatively small warehouse with 20 order pickers, 10 with a dominant prevention focus and 10 with a dominant promotion focus. According to a study among HR departments in the United States, the median expected salary for a typical order picker in the United States is $\$ 29,049$ (Salary.com, 2013). This implies that the total annual salary costs for the order pickers in this situation are approximately $\$ 581,000$. The following example shows the possible consequences of implementing the findings of the experiment. 


\section{Example}

Assume the warehouse uses a zone picking system combined with an individual incentive system. In this case, switching to a cooperation-based incentive system would increase productivity by 34\% (Table 11). This means that the same amount of work could be done by 15 pickers instead of $20(20 / 1.34=14.9)$. Although this might also lead to a $64.7 \%$ increase in errors, employing one person as quality inspector should mitigate this problem. Taking regulatory focus also into account by changing the dominant regulatory focus of five employees from a prevention focus to a promotion focus leads to an additional productivity increase. In the original situation (10 employees dominantly promotion-focused, 10 dominantly prevention-focused), we would expect a relative productivity score of $135.7((147.5+123.9) / 2)$. However, now (15 promotion focused, 5 prevention focused) we expect a score of $141.6((15 \times 147.5+5 \times 123.9) / 20)$, an additional productivity increase of $4.3 \%$. Also the expected number of errors is expected to reduce by $24.9 \%$. We conservatively assume that in this situation the company would be able to employ four fewer people, corresponding to more than $\$ 116,000$ savings in yearly wage costs $(4 \times 29,049)$, or $20 \%$ of the total annual salary costs of the order pickers.

\section{Implementation}

For most companies, the potential positive effects of implementing an incentive system in general are probably no surprise. However, the best type of incentive and the magnitude of the effects of the choice between incentive systems might be not so well known. It should be emphasized that this study only compares a team-oriented and a competition-based incentive system. Most likely, the benefits for companies that currently do not have an incentive system are even larger. According to a meta-analysis by Condly et al. (2003), incentive systems deliver overall average performance gains of $22 \%$ compared to a situation without incentive systems. Implementing the findings of this study in practice requires incentives that can be realistically made part of the company's reward structure. For individual incentives, an example of this is employing piece-rate pay in addition to a base wage. In our situation, this could be paying employees an additional amount per completed pick or order (a statistic registered by many warehouses already). Something similar could be implemented at the team level, in which case the additional amount is based on the team performance. It should be noted that also non-monetary incentives, such as small prizes or privileges, can be effective (Jeffrey and Shaffer, 2007). 
Regulatory focus is relatively easy to measure with a questionnaire. As many warehouses use multiple picking methods in different parts of the facility (De Koster et al., 2007), companies might try to assign people with a particular regulatory focus to the right type of picking process, or even use regulatory focus as one of the selection criteria in the hiring process. As we have found, people with a dominant promotion focus are more productive in a parallel picking method with a competition-based incentive system, whereas people with a dominant prevention focus are more productive in a zone picking method with a cooperation-based incentive system. To make use of this, companies can re-assign employees with a particular dispositional regulatory focus to tasks that are better aligned with their regulatory focus. However, depending on the methods used, this option might not be present. Alternatively, the regulatory focus of a person can be influenced by situational cues. Companies can evoke a promotion or prevention focus by framing the tasks in particular ways. For example, to evoke a promotion focus, companies will have to frame the task in terms of potential gains, whereas a prevention focus can be evoked by framing the task in terms of potential losses (Crowe and Higgins, 1997).

\subsection{Implications for theory}

Through this experiment, we found that aligning the right incentive system with the right picking method can lead to increased productivity and quality. In particular, parallel picking works best in terms of productivity in combination with a competition-based incentive system (hypothesis 1a), whereas zone picking performs optimally with a cooperation-based incentive system (hypothesis 2a). For dynamic zone picking, the difference between the two incentive systems was negligible. This result neatly confirms the theory that individualized incentive schemes are more effective when the task is more independent (such as parallel order picking), whereas cooperation-based incentive schemes are more effective if the task requires interdependent operation. We also found that competition-based incentives in parallel picking lead to fewer errors, which is in line with hypothesis 1b. However, competitive-based incentives also proved to relate to fewer errors in zone picking, which contradicts hypothesis $2 \mathrm{~b}$. For errors as performance measure, we were not able to find support for most of the hypotheses $(2 b, 3 b, 4 b$, and $5 b)$. The theory on which these hypotheses were based was not strongly developed, and the results suggests that the relative scarcity of such theory might reflect empirical reality. 
Furthermore, the results that show the influence of the combination of regulatory focus, method, and incentive system on productivity are novel. The difference between the two incentive systems was indeed the largest for people with a dominant promotion focus in parallel picking (hypothesis $3 a$ ), and for people with a dominant prevention focus in zone picking (hypothesis 4a). In dynamic zone picking, people with a dominant promotion or dominant prevention focus performed similarly (hypothesis 5a). The performance improvement realized by optimally combining these factors illustrates the impact that regulatory focus and incentive systems can have in addition to the choice of a picking method. This is most likely not only relevant to the context of order picking, but could be applicable to all types of repetitive labor. Investigating this in a different context while possibly taking other behavioral factors into account could be interesting in this respect.

\section{$\underline{5.3 \text { Strengths and Limitations }}$}

The use of a controlled field experiment in a setting that represents the situation in practice is an evident strength of this study. This provides the required academic rigor, and enables a smooth translation of the findings to practice at the same time. However, like all academic research, this study is subject to several limitations. First of all, a larger sample size would have been preferable to ensure that the effects that occur are statistically noticeable. Still, 142 participants is an acceptable number in the $3 \times 2$ between-subjects design that was employed. Second, the academic students that participated in the experiment are probably less representative of order pickers. However, we tried to mitigate this problem by including professional order pickers (approximately one third of the total sample), and logistics students training to become future warehouse employees (half of the sample). This should ensure sufficient external validity to generalize the results to workers in practice. Third, the relatively short time scale of the experiment could endanger the generalizability. In terms of productivity and quality, the performance could be influenced by the fact that the experiment only required 20 minutes of order picking, of which only 10 minutes were used for data collection. Doing the job for a complete day, week, or even year, could potentially alter the results. For example, pickers might be satisfied with a certain picking method in combination with a specific incentive system for 20 minutes, but could become dissatisfied after a longer period. Still, the relatively short time scale is inherent to our experimental setup. 


\section{$\underline{5.4 \text { Conclusion }}$}

Aligning regulatory focus, incentive systems, and order picking methods helps to close the gap that exists between operations management theories and their applicability to practical settings. The use of a controlled field-experiment which included both professional order pickers and students as participants has enabled us to obtain results that are generalizable to practice without compromising on scholarly rigor.

\section{References}

Beersma, B., Homan, A.C., Van Kleef, G.A., De Dreu, C.K.W., 2013. Outcome interdependence shapes the effects of prevention focus on team processes and performance. Organizational Behavior and Human Decision Processes 121, 194-203.

Bliese, P., 2009. Multilevel Modeling in R (2.3)-A Brief Introduction to R, the multilevel package and the nlme package.

Bliese, P.D., Halverson, R.R., 1998. Group size and measures of group-level properties: An examination of etasquared and ICC values. Journal of Management 24, 157-172.

Bliese, P.D., Halverson, R.R., 2002. Using Random Group Resampling in multilevel research: An example of the buffering effects of leadership climate. The Leadership Quarterly 13, 53-68. doi:http://dx.doi.org/10.1016/S1048-9843(01)00104-7

Caron, F., Marchet, G., Perego, A., 1998. Routing policies and COI-based storage policies in picker-to-part systems. International Journal of Production Research 36, 713-732.

Caron, F., Marchet, G., Perego, A., 2000. Optimal layout in low-level picker-to-part systems. International Journal of Production Research 38, 101-117.

Condly, S.J., Clark, R.E., Stolovitch, H.D., 2003. The Effects of Incentives on Workplace Performance: A Metaanalytic Review of Research Studies 1. Performance Improvement Quarterly 16, 46-63.

Crowe, E., Higgins, E.T., 1997. Regulatory focus and strategic inclinations: Promotion and prevention in decisionmaking. Organizational behavior and human decision processes 69, 117-132.

De Koster, R., 2007. Warehouse Assessment in a Single Tour, in: Lahmar, M. (Ed.), Facility Logistics: Approaches and Solutions to Next Generation Challenges. Auerbach Publications, New York, NY, pp. 39-60. 
De Koster, R., Le-Duc, T., Roodbergen, K.J., 2007. Design and control of warehouse order picking: A literature review. European Journal of Operational Research 182, 481-501.

DeMatteo, J.S., Eby, L.T., Sundstrom, E., 1998. Team-based rewards: current empirical evidence and directions for future research. Research in organizational behavior 20, 141-183.

Dickinson, D.L., Isaac, R.M., 1998. Absolute and relative rewards for individuals in team production. Managerial and Decision Economics 19, 299-310.

Digman, J.M., 1990. Personality structure: Emergence of the five-factor model. Annual review of psychology 41, $417-440$.

Dobbins, G.H., Cardy, R.L., Carson, K.P., 1991. Examining fundamental assumptions: A contrast of person and system approaches to human resource management. Research in personnel and human resources management $9,1-38$.

Doerr, K.H., Freed, T., Mitchell, T.R., Schriesheim, C.A., Zhou, X.T., 2004. Work flow policy and within-worker and between-workers variability in performance. Journal of Applied Psychology 89, 911.

Eisenberger, R., Cameron, J., 1996. Detrimental effects of reward: Reality or myth? American psychologist 51, 1153.

Elsayed, E.A., 1981. Algorithms for optimal material handling in automatic warehousing systems. The International Journal of Production Research 19, 525-535.

Erez, M., Somech, A., 1996. Is group productivity loss the rule or the exception? Effects of culture and group-based motivation. Academy of Management Journal 39, 1513-1537.

Frazelle, E., 2002. World-class warehousing and material handling. McGraw-Hill New York.

Freitas, A.L., Higgins, E.T., 2002. Enjoying goal-directed action: The role of regulatory fit. Psychological Science 13, $1-6$.

Goetschalckx, M., Donald Ratliff, H., 1988. Order picking in an aisle. IIE transactions 20, 53-62.

Gomez-Meja, L.R., Balkin, D.B., 1989. Effectiveness of individual and aggregate compensation strategies. Industrial Relations: A Journal of Economy and Society 28, 431-445.

Guzzo, R.A., Jette, R.D., Katzell, R.A., 1985. The effects of psychologically based intervention programs on worker productivity: A meta-analysis. Personnel Psychology 38, 275-291. 
Hackman, J.R., Oldham, G.R., 1974. The job diagnostic survey: an instrument for the diagnosis of jobs and the evaluation of job redesign projects. New Haven, Conn,.

Halvorson, H.G., Higgins, E.T., 2013. Do you play to win--or to not lose? Harvard business review 91, 117-120.

Higgins, E.T., 1997. Beyond pleasure and pain. American Psychologist 52, 1280-1300.

Higgins, E.T., 1998. Promotion and prevention: Regulatory focus as a motivational principle. Advances in experimental social psychology $30,1-46$.

Higgins, E.T., 2000. Making a good decision: value from fit. The American psychologist 55, 1217-1230.

Hsieh, L., Tsai, L., 2006. The optimum design of a warehouse system on order picking efficiency. The International Journal of Advanced Manufacturing Technology 28, 626-637.

Hwang, H.S., Cho, G.S., 2006. A performance evaluation model for order picking warehouse design. Computers \& Industrial Engineering 51, 335-342.

Hwang, H.S., Oh, Y.H., Lee, Y.K., 2004. An evaluation of routing policies for order-picking operations in low-level picker-to-part system. International Journal of Production Research 42, 3873-3889.

Jane, C.-C., Laih, Y.-W., 2005. A clustering algorithm for item assignment in a synchronized zone order picking system. European Journal of Operational Research 166, 489-496.

Jarvis, J.A.Y.M., McDowell, E.D., 1991. Optimal Product Layout in an Order Picking Warehouse. IIE Transactions $23,93-102$.

Jeffrey, S.A., Shaffer, V., 2007. The motivational properties of tangible incentives. Compensation \& Benefits Review $39,44$.

Jenkins, G.D., Gupta, N., 1981. Financial incentives and productivity improvement. Department of Management, College of Business Administration and Graduate School of Business, University of Texas at Austin.

Jenkins Jr, G.D., Mitra, A., Gupta, N., Shaw, J.D., 1998. Are financial incentives related to performance? A metaanalytic review of empirical research. Journal of Applied Psychology 83, 777.

Kanfer, R., Chen, G., Pritchard, R.D., 2008. Work Motivation: Past, present and future. CRC Press.

Kark, R., Van Dijk, D., 2007. Motivation to lead, motivation to follow: The role of the self-regulatory focus in leadership processes. Academy of Management Review 32, 500-528. doi:10.2307/20159313 
Kohn, A., 1993a. Punished by rewards: The trouble with gold stars, incentive plans, A's, praise, and other bribes. Houghton, Mifflin and Company.

Kohn, A., 1993b. Why incentive plans cannot work. Harvard business review 71.

Lanaj, K., Chang, C.-H.D., Johnson, R.E., 2012. Regulatory focus and work-related outcomes: A review and metaanalysis. Psychological bulletin 138, 998-1034. doi:10.1037/a0027723

Lazear, E.P., 2000. Performance Pay and Productivity. The American Economic Review 90, 1346-1361. doi: $10.2307 / 2677854$

Le-Duc, T., De Koster, R., 2005. Travel distance estimation and storage zone optimization in a 2-block class-based storage strategy warehouse. International Journal of Production Research 43, 3561-3581.

Lee, A.Y., Aaker, J.L., Gardner, W.L., 2000. The pleasures and pains of distinct self-construals: the role of interdependence in regulatory focus. Journal of personality and social psychology 78, 1122.

Lenth, R. V., 2013. lsmeans: Least-squares means package for R, version 1.10-2.

Locke, E.A., 1968. Toward a theory of task motivation and incentives. Organizational behavior and human performance 3, 157-189.

Locke, E.A., Feren, D.B., McCaleb, V.M., Shaw, K.N., Denny, A.T., 1980. The relative effectiveness of four methods of motivating employee performance. Changes in working life 363, 388.

Locke, E.A., Shaw, K.N., Saari, L.M., Latham, G.P., 1981. Goal setting and task performance: 1969-1980. Psychological bulletin 90, 125.

Lockwood, P., Jordan, C.H., Kunda, Z., 2002. Motivation by positive or negative role models: regulatory focus determines who will best inspire us. Journal of personality and social psychology 83,854 .

Nakagawa, S., Schielzeth, H., 2013. A general and simple method for obtaining R2 from generalized linear mixedeffects models. Methods in Ecology and Evolution 4, 133-142. doi:10.1111/j.2041-210x.2012.00261.x

Petersen, C., 2004. A comparison of picking, storage, and routing policies in manual order picking. International Journal of Production Economics 92, 11-19.

Pinheiro, J., Bates, D., DebRoy, S., Sarkar, D., R Core Team, 2013. Linear and Nonlinear Mixed Effects Models.

R Core Team, 2013. R: A Language and Environment for Statistical Computing. 
Ratliff, H.D., Rosenthal, A.S., 1983. Order-picking in a rectangular warehouse: a solvable case of the traveling salesman problem. Operations Research 31, 507-521.

Ree, M.J., Earles, J.A., Teachout, M.S., 1994. Predicting job performance: Not much more than g.. Journal of Applied Psychology 79, 518.

Rosenwein, M.B., 1996. A comparison of heuristics for the problem of batching orders for warehouse selection. International Journal of Production Research 34, 657-664.

Salary.com, 2013. U.S. National Average Wage Order Picker [WWW Document]. Salary Wizard. URL http://www1.salary.com/Order-Picker-Salary.html

Schultz, K.L., Juran, D.C., Boudreau, J.W., 1999. The Effects of Low Inventory on the Development of Productivity Norms. Management Science 45, 1664-1678. doi:10.1287/mnsc.45.12.1664

Schultz, K.L., McClain, J.O., Thomas, L.J., 2003. Overcoming the dark side of worker flexibility. Journal of Operations Management 21, 81-92. doi:http://dx.doi.org/10.1016/S0272-6963(02)00040-2

Shah, J., Higgins, E.T., 2001. Regulatory concerns and appraisal efficiency: the general impact of promotion and prevention. Journal of personality and social psychology 80, 693 .

Shah, J., Higgins, T., Friedman, R.S., 1998. Performance incentives and means: how regulatory focus influences goal attainment. Journal of personality and social psychology 74, 285.

Shepperd, J.A., 1993. Productivity loss in performance groups: A motivation analysis. Psychological bulletin 113, 67.

Shieh, G., 2012. A comparison of two indices for the intraclass correlation coefficient. Behavior research methods 44, $1212-1223$.

Sundstrom, E., De Meuse, K.P., Futrell, D., 1990. Work teams: Applications and effectiveness. American psychologist $45,120$.

Tjosvold, D., 1986. The dynamics of interdependence in organizations. Human Relations 39, 517-540.

Tompkins, J.A., 2010. Facilities planning. Wiley.

Wageman, R., 1995. Interdependence and group effectiveness. Administrative science quarterly 145-180.

Wageman, R., Baker, G., 1997. Incentives and cooperation: The joint effects of task and reward interdependence on group performance. Journal of organizational behavior 18, 139-158. 
Wallace, C., Chen, G., 2006. A Multilevel Integration of Personality, Climate, Self-Regulation, and Performance. Personnel Psychology 59, 529-557.

Wallace, J.C., Johnson, P.D., Frazier, M.L., 2009. An examination of the factorial, construct, and predictive validity and utility of the regulatory focus at work scale. Journal of Organizational Behavior 30, 805-831.

Wallace, J.C., Little, L.M., Shull, A., 2008. The moderating effects of task complexity on the relationship between regulatory foci and safety and production performance. Journal of Occupational Health Psychology 13, 95.

Yu, M., 2008. Enhancing warehouse performance by efficient order picking. Erasmus University Rotterdam.

Zhou, R., Pham, M.T., 2004. Promotion and prevention across mental accounts: When financial products dictate consumers' investment goals. Journal of Consumer Research 31, 125-135.

Zingheim, P.K., Schuster, J.R., 2000. Pay people right!: Breakthrough reward strategies to create great companies. Jossey-Bass Publishers, San Francisco, CA. 


\begin{tabular}{|c|c|}
\hline \multicolumn{2}{|c|}{ ERIM Report Series Research in Management } \\
\hline ERIM Report Series reference number & ERS-2015-009-LIS \\
\hline Date of publication & $2015-07-09$ \\
\hline Version & 09-07-2015 \\
\hline Number of pages & 39 \\
\hline Persistent URL for paper & http://hdl.handle.net/1765/78365 \\
\hline Email address corresponding author & jvries@rsm.nl \\
\hline Address & $\begin{array}{l}\text { Erasmus Research Institute of Management } \\
\text { (ERIM) } \\
\text { RSM Erasmus University / Erasmus School } \\
\text { of Economics } \\
\text { Erasmus University Rotterdam } \\
\text { PO Box } 1738 \\
3000 \text { DR Rotterdam, The Netherlands } \\
\text { Phone: +31104081182 } \\
\text { Fax: +31104089640 } \\
\text { Email: info@erim.eur.nl } \\
\text { Internet: http://www.erim.eur.nl }\end{array}$ \\
\hline Availability & $\begin{array}{l}\text { The ERIM Report Series is distributed } \\
\text { through the following platforms: } \\
\text { RePub, the EUR institutional repository } \\
\text { Social Science Research Network (SSRN) } \\
\text { Research Papers in Economics (RePEc) }\end{array}$ \\
\hline Classifications & $\begin{array}{l}\text { The electronic versions of the papers in the } \\
\text { ERIM Report Series contain bibliographic } \\
\text { metadata from the following classification } \\
\text { systems: } \\
\text { Library of Congress Classification (LCC) } \\
\text { Journal of Economic Literature (JEL) } \\
\text { ACM Computing Classification System } \\
\text { Inspec Classification Scheme (ICS) }\end{array}$ \\
\hline
\end{tabular}

